\title{
Life's journey of an academic with bipolar disorder
}

\section{Introduction}

I am an academic who has journeyed through life with many episodes of depression and two episodes of hypomania within a time span of twelve years. I have been treated by five psychiatrists, over twelve years. In this article I describe the suffering I went through and also the process of recovery. In my journey I benefitted most when the psychiatrist engaged in conversation in addition to prescribing medication, and I think both are equally important.

\section{My experience of depression}

For the first 28 years of my life I did not experience any psychological symptoms of depression. However, in 2006 at the age of 29 years, I began to experience symptoms of depression, and suffered enormously from it. When I initially developed symptoms of depression, I was away from home. I was in the UK reading for my $\mathrm{PhD}$. I encountered problems with my $\mathrm{PhD}$ supervisor, which contributed to mydepression. This was aggravated by my having to do odd jobs along with my studies, as my parents could not financially support me.

I found the psychological symptoms of depression very difficult. For example, I used to cry for hours, locked up all alone in my room. Whenever I had access to free alcohol, especially when attending conferences, I consumed it in excess, as it helped me to forget my sadness temporarily.

There were social factors too which lowered my mood further. For example, I tried hard to find part-time jobs to support myself, and initially I was able to find an odd job selling sweets in the Manchester United Football Club. On other days I worked in the bar of the Manchester United Football Club. Having been born and bred in Sri Lanka, I found it difficult to understand the accent of the people who came to the bar to buy beer. As a result, when I delayed to serve them they would shout out saying "you f**** woman what are you doing?” I was helpless but had to continue doing this job until I found another job. There were biological factors too which contributed towards my depression. For example, I had to spend every penny that I earned on my tuition fees and accommodation. Consequently, most often I didn't have enough food to eat, or ate an apple. I worked late hours to earn and then got up early morning to work on my $\mathrm{PhD}$ thesis. Therefore, I did not have adequate sleep.
Every time I went through an episode of depression I had suicidal inclinations. I recall listening to the song 'Seasons in the Sun' by Foster and Allen, where they sing;

"Good bye to you my trusted friend ....it is hard to die when all the birds are singing in the sky now that spring is in the air..."

Similarly, though I had suicidal ideas, at the same time it was hard for me to do so, because I thought about my family members who loved me so much.

I returned to Sri Lanka in September 2006 to collect data for my study, as it was a case study relevant to the Sri Lankan context. But after I came back, nobody, not even my family members understood that I was going through depression. My parents wondered why I spoke so softly. My sister said that I was not the same person I used to be. My sister and I used to have chats, but now I preferred to be on my own. We did not even fight like we used to do. Almost every four hours I wanted to cry. Then a change came over me. From being a silent and subdued character, I became irritable and aggressive. It was during this time that a friend of my sister suggested that I should see a psychiatrist. My parents took me to a psychiatrist and I was given an anti-depressant, which gave me temporary relief.

After completing the data collection process, I went back to the UK in January 2008. In January 2010, I submitted my PhD Thesis, but was only awarded a MPhil. I felt that all my dreams were shattered; I became extremely depressed. I felt the only thing I could do was commit suicide. The anti-depressant that had been prescribed seemed no longer effective. I came back to Sri Lanka in January 2010; I continued to struggle with my feelings of depression.

\section{Ongoing medication}

In June 2010, I sought the help of another psychiatrist, who prescribed several sessions of electroconvulsive therapy and anti-depressant treatment. This brought about my recovery.

However during the next five to six years I experienced several more episodes of depression, which was very difficult for me. Over this time I was treated with several antidepressants, a mood stabilizer and electroconvulsive therapy. I think certain events that occurred at my workplace may have contributed to my episodes of depression. But I realized that the psychiatrists only went 
so far, and treated only the symptoms of my illness and failed to address the causal factors underlying my symptoms.

\section{Conversation}

In February 2016, I went to a psychiatrist who approached my depression by means of both medication and conversation. The psychiatrist posed probing questions; through our conversations I began to understand myself better. I have always lacked self-confidence and selfworth. I always allowed the 'other person' to win. From my childhood, I remember being controlled at home by my parents and grandparents, and I was considered to be an 'innocent and obedient' child. My sister, who was five years younger to me, due to her inborn traits was more dominant than me. Even at school my schoolmates dominated me. I remember standing in the canteen queue buying food for other girls who didn't want to stand in the queue to buy food! This also affected my behaviour after I started working. Looking back I feel that my behavior has been passive from childhood.

Through our conversations the psychiatrist encouraged me to reflect on why I had become such a passive person. I couldn't answer these questions. Trying to answer these questions made me feel extremely sad, with feelings of self-pity. It was not easy. While having therapy, I experienced some work-place stressors and I became depressed again. But I kept taking medication and continued talking to the psychiatrist. Through this I felt encouraged and I was determined that I would change. I was able to discuss some of my future life-goals, such as completing a $\mathrm{PhD}$, and getting married; and also discuss my fears around marriage. I felt that these conversations helped me understand myself better.

\section{Mood shifts}

But from mid 2016 I started becoming over confident at home, at my workplace, at Church and wherever I went. I was continuously analyzing, drawing causal chains, and there were racing of thoughts, which made me think that I was extremely smart. In spite of taking sleeping tablets I could not sleep for more than two hours at night, and my insomnia was a disturbance to my family members. I became very religious and spent hours in prayer. I often asked my family members to join me in prayer, especially in the night. I told them that God had touched me. When I attended the aerobics class I felt that I had enormous energy and kept over exercising. I sat at the computer for long hours, writing my life story. I seemed to be losing control over myself, spoke very loudly and gave long explanations for any questions raised. I was also very emotional with all who interacted with me.

My parents whom I live with, and my sister understood that there was a change coming over me. However, none of us had ever heard of the term hypomania. I think my family was puzzled and worried about these changes. Finally I was diagnosed to be suffering from hypomania. At this point it was diagnosed that I had a bipolar disorder. This first episode of hypomania lasted for several months; Towards the end of 2016, I finally recovered from this hypomanic condition.

\section{What next?}

When I am not experiencing depression or hypomania, I have attempted to become a more assertive person. I have understood that becoming assertive is a trait, which needs to be inculcated and developed. The strengths of a person can help to inculcate this habit. My own strengths are my sense of determination and perseverance in learning, commitment and research orientation. To be an assertive person I have to know what I want in life and be able to attain it.

And I have come to understand that a person cannot attain what he or she wants in life without being aware of the behavior of people around. Therefore, other people's thoughts and emotions have to be understood. For this, it is important to manage relationships,and to develop communication skills. Realising this, I am focusing on improving my communication skills, to get on better with others and to attain what I want in life.

\section{Conclusions}

Illnesses due to psychological issues are just as painful as illness due to physical issues. However, mentalillnesses are not identified by society until the symptoms get aggravated. In treating mental illness, the focus is on medication. But I have found by experience that medication alone will not suffice. Conversation is also as important. From personal experience I know it is of paramount importance to have a dialogue between the psychiatrist and the patient. This conversation should be extended to the family members so that they too can support the patient. 